\title{
Peak fitting and modelling of NOM removal by coagulation from River Murray water in South Australia
}

\author{
$\underline{\text { Z. Aslam }}^{\mathrm{a}}$, Murshed. M. F ${ }^{\mathrm{a}}$, J. van Leeuwen ${ }^{\mathrm{ac}}$, Christopher W.K. Chow ${ }^{\mathrm{a}, \mathrm{b}, \mathrm{c}}$ and Mary Drikas ${ }^{\mathrm{a}, \mathrm{b}, \mathrm{c}}$ \\ ${ }^{a}$ South Australian Centre for Water Management and Reuse, School of Natural and Built Environments, \\ University of South Australia, SA 5095, Australia. \\ ${ }^{b}$ Australian Water Quality Centre, South Australian Water Cooperation, Adelaide, SA 5000, Australia. \\ ${ }^{c}$ State Key Laboratory for Environmental Aquatic Chemistry, CAS, China
}

Email:aslzy001@mymail.unisa.edu.au

\begin{abstract}
Removal of natural organic matter (NOM) remains a major challenge confronting the water industry in Australia, in the supply of safe drinking water. Its treatability can vary depending on its character and this may be enhanced by optimising the inorganic coagulant dose and depending on the coagulant type, the coagulation $\mathrm{pH}$. Generally, in coagulation modelling input parameter like $\mathrm{pH}$, UV abs $254 \mathrm{~nm}$, turbidity and colour have been used in modelling approaches. However UV abs 254nm and colour does not comprehensively describe the character of NOM and improved characterization techniques should lead to better assessment of treatability of water by conventional treatment process.
\end{abstract}

Investigation was conducted on data obtained from high performance size exclusion chromatography (HPSEC) of NOM to assess the potential of using this for estimating the removal of dissolved organic carbon (DOC) under simulated conventional treatment process. Controlled jar testing using various doses from low to high $(60$ to $200 \mathrm{mg} / \mathrm{L})$ and at different coagulation $\mathrm{pH}$ levels, from 5.5 to 8.5 was conducted under laboratory conditions. Using raw water, collected from the Morgan Water Treatment Plant (WTP), water quality parameters such as $\mathrm{pH}$, UV abs $254 \mathrm{~nm}$, DOC, turbidity, colour and HPSEC before and after treatment were recorded. The basis of this study was to;

- Determine the removal of DOC in relation to its character by application of various coagulant doses.

- Determine the applicability of using a peak fitting technique to analyse HPSEC data for determination of treatability of NOM in water

A peak fitting technique was used to evaluate data of HPSEC analysis to explore the character of organics peak fitting data was obtained for modelling after resolving a range of peaks, representing organics with various molecular weight profiles from the HPSEC chromatogram. The fitted peak areas of organics in raw water were calculated and compared with those of treated water to investigate the removable or nonremovable components by using low to high alum doses. Much less removal of lower molecular weight (nonhumic substances) compounds occurred compared with removals of higher molecular (humic substances) compounds showing the lower molecular weight compounds are generally recalcitrant to removal by coagulation. Models were developed that relate HPSEC peak area removal with alum dose, and molecular weight with their removals at controlled $\mathrm{pH}$. The basis of this study was to establish suitable tools for evaluation and identification of coagulable NOM fractions and optimum treatment conditions. Here, we report the development of a model specially designed using peak fitting data for HPSEC molecular weight profile of treated water, to enable prediction of percentage area removal by coagulation. The key aim is to provide reliable information of the character of NOM in order to optimize treatment for its removal. The model was developed from data of waters from the Morgan Water Treatment Plant (South Australia).

Key words: NOM, Modelling, HPSEC, Peak Fitting, Peaks Area 


\section{INTRODUCTION}

Drinking water quality, before and after treatment is a fundamental issue for water treatment plant operators and the water industries, in ensuring water supplied is safe and aesthetically acceptable to consumers. Colour, natural organic matter (NOM) and turbidity are key contaminants present in source waters that need to be removed or minimized before supply and the most common water treatment process incorporates the use of inorganic metal coagulants for their removals. NOM consists of a complex mixture of organic compounds from a range of sources including live and dead flora, microbes and aquatic organisms of autochthonous and allochthonous origins. Modelling of water treatment processes have been reported for removal of organics, for example, Bazer-Bachi et al. (1990), Baxter et al. (1999), Edwards, (1997), van Leeuwen et al., (2003 and 2005 ) and Kastl et al. (2004). These models were typically based on experiential relationships between raw and treated water quality and treatment conditions required to achieve a targeted water quality. Coagulation experiments using the jar test procedure can provide important information on the removal of NOM but less on the basis for removals, such as the character of the NOM. High performance size exclusion chromatography (HPSEC) is an informative method to evaluate molecular sizes of humic substances from different sources and it can be applied to study the character of NOM before and after treatment (Chow et al., 2008 and Goslan et al., 2004). Currently, there are few models developed that relate the character of NOM to its treatability by coagulation. In the study reported here, the analytical technique, high performance size exclusion chromatography was performed to better understand the removal of various organic components with alum treatment. This technique provides restricted information due to low separation of the various organic components distribution. To address this, peak fitting was applied with the aim to resolve overlapping peaks of the HPSEC data, and to identify the various molecular weights of the constituent organics. Based on total area removal for each peak before and after coagulation a mathematical model is proposed which describes the removal potential of these identified peak based upon their average molecular weights. Further, regression analysis was performed to identify the correlation between DOC removal and total peak area removal, for different coagulant doses and $\mathrm{pH}$ levels.

\section{MATERIALS AND METHODS}

\subsection{Data collection and Sampling}

In order to generate data from which a model as detailed above could be developed, jar testing was conducted on water samples collected from the Morgan Water Treatment Plant located (169km in north of Adelaide) adjacent to the River Murray, South Australia. Raw water was collected in October 2010 for all jar tests. Water samples were stored at $4^{\circ}$ prior to jar testing.

Dissolved organic carbon (DOC) analysis: DOC concentrations of water samples (filtered through $0.45 \mu \mathrm{m}$ ) were determined using a total carbon analyser (Model 820, Sievers Instruments Inc., USA) and indirectly by measuring the absorbance at $254 \mathrm{~nm}$ using a UV/VIS spectrophotometer (Model 918, GBC, Australia)with a $1 \mathrm{~cm}$ quartz cell.

Turbidity: Turbidity, in nephelometric turbidity unit (NTU), was measured using a Hach ratio turbidimeter (Model 2100 AN,Co., USA).

Colour: Colour, in Hazen units (HU) was determined by measuring the absorbance at $456 \mathrm{~nm}$ using UV.VIS spectrophotometer (Model 918,CBG, Australia).

Jar Testing: Jar test were performed on water at room temperature, as previously described (van Leeuwen et al. 1999b). Aluminium sulphate $\left(\mathrm{Al}_{2}\left(\mathrm{SO}_{4}\right)_{3} \cdot 18 \mathrm{H}_{2} 0\right)$ was used as a coagulant in this jar test study. Reagent used for controlling the $\mathrm{pH}$ of water sample was sulphuric acid, AnalaR ${ }^{\circledR} 98 \%$ and sodium hydroxide. Samples were filtered (Whatman No.1) to measure the filtered turbidity and subsequently through $0.45 \mu \mathrm{m}$ to measure colour, UV, DOC and through $0.22 \mu \mathrm{m}$ for HPSEC.

\subsection{Peak Fitting Technique and Modelling}

For the peak fitting model, apparent molecular weight was converted to eluting time (retention time) to keep the centre (average molecular weight) of the peaks constant, within a difference of ( \pm 0.1 second). For deconvolution of the peaks, an initial optimization provided by the Peak fit tool (Version 4, Systat Software Inc.) was used resulting in $\mathrm{R}^{2}$ value of $(0.96 \pm 0.03)$ for fitted Log Normal- 4 areas. These shapes of peak areas were chosen as the best peak type to represent the raw water. Raw water NOM peaks were further selected to predict the percentage reduction of peaks area measured by UV absorption, after each successive coagulant 
Aslam et al., Peak fitting and modelling of NOM removal by coagulation from River Murray...

dose. After selection of the peak fitting procedure, it was evident that all HPSEC chromatographic peaks can be resolved into individual peaks and optimized to maximise $\mathrm{R}^{2}$. Models were developed using Table Curve (C) software 2D Windows v4.00.

\section{RESULTS AND DISCUSSION}

\subsection{Removal of natural organic compounds (measured as DOC) by alum treatment.}

The results of jar tests conducted on River Murray water (at Morgan) with pH control ranging from 5 to 8.5 are shown in Figure 1. From this figure it is evident that there were some DOC components in the treated water that are recalcitrant to removal by alum treatment; i.e. the rates of removal decrease with increasing alum dose, though this is also a function of $\mathrm{pH}$, i.e. at $\mathrm{pH} 8.5$, the residual DOC concentrations in treated water was highest. For additional removal of DOC, the $\mathrm{pH}$ needs to be reduced, which is optimized between 5 and 6 . However, if the $\mathrm{pH}$ is too low, near $\mathrm{pH} 5$, the residual aluminium in treated water becomes too high and hence the overall optimum $\mathrm{pH}$ is $\sim 6$. Where, however, raw water DOC levels are high, a water industry may need to apply high alum doses and optimize coagulation $\mathrm{pH}$ in order to comply with limits in disinfection by product compound concentrations. Residual organic compounds present in water after treatment react with chlorine to form disinfection by products.

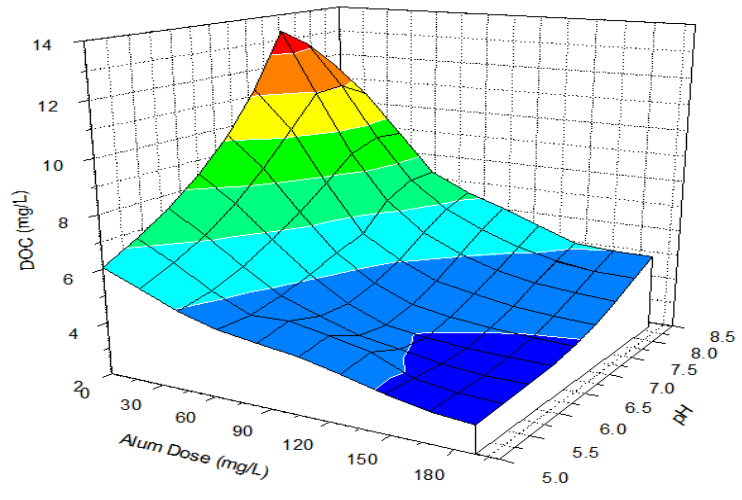

Figure 1: Relationship between DOC removal at different alum dose and $\mathrm{pH}$ for Morgan water

\subsection{Peak-Fitting Model}

Treated water samples from jar tests (that had been treated at 60, 110 and 200mg/L) and coagulated at constant $\mathrm{pH}$ 6, were further analysed by HPSEC with UV detection to investigate the molecular weight distribution (MWD) profiles of NOM.These were then compared with the MWD of the raw water. The HPSEC chromatograms and the results of peak fittings are shown in Figure 2. The peak-fitting procedure selected for this study was of two steps: optimization and analysis. First the optimization step determined the optimum peak fitting parameters, such as peak type and fitting method (Log Normal-4 Area, refine shape and select peak centre constants). In the second stage, chromatograms of test and other samples were also analysed for background responses to build the peak-fitting model. The peak area under each peak was subsequently determined.
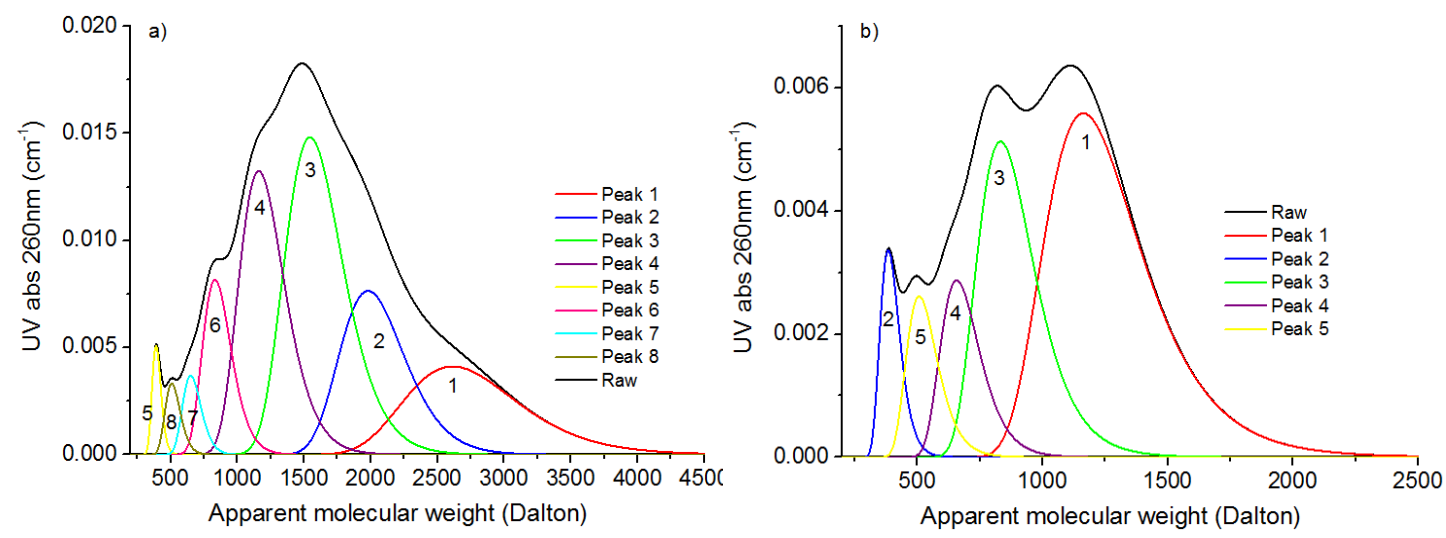
Aslam et al., Peak fitting and modelling of NOM removal by coagulation from River Murray...

Figure 2: Example of peak area generated from Peak Fitting software based on molecular weight profile from HPSEC results before and after coagulation; (a) Peak area of raw water and (b) Peak area after $60 \mathrm{mg} / \mathrm{L}$ alum

\subsection{Character of NOM as found by HPSEC and Peak-fitting.}

The removal of NOM by alum treatment (measured as DOC) was determined in terms of percentage area removal of each identified peak after treatment. Eight peaks were identified in the raw water NOM profile and apparent molecular weights of the resolved peaks determined are shown in the Table 1. These peaks are as follows: Peak 1 (2565 Da), Peak 2 (1908Da), Peak 3 (1592Da), Peak 4 (1127Da), Peak 5 (785Da), Peak 6 (623Da), Peak 7 (479 Da) and Peak 8 (368 Da). These peaks can be associated with different chemical groups, biological residue and lower molecular weight nitrogen containing organic compounds as described by Chow et al. (2008). Application of high alum dose in this study was to demonstrate NOM capacity removal for that water only, but this level of dosing is usually practically infeasible due to the high production of sludge at the water treatment plant and a more practical dose for the water tested is nearer to $110 \mathrm{mg} / \mathrm{L}$.

Table 1: Percentage area removal for each peak for different coagulant dose

\begin{tabular}{ccccc}
\hline Peaks & Molecular weight & \multicolumn{3}{c}{$\begin{array}{c}\text { Percentage area removal } \\
\text { for each peak }(\%)\end{array}$} \\
\hline No. & Dalton & $60 \mathrm{mg} / \mathrm{L}$ & $110 \mathrm{mg} / \mathrm{L}$ & $200 \mathrm{mg} / \mathrm{L}$ \\
Peak 1 & 2565 & 100.0 & 100.0 & 100.0 \\
Peak 2 & 1908 & 100.0 & 100.0 & 100.0 \\
Peak 3 & 1592 & 100.0 & 100.0 & 100.0 \\
Peak 4 & 1127 & 52.2 & 88.3 & 93.2 \\
Peak 5 & 785 & 32.7 & 54.8 & 65.6 \\
Peak 6 & 623 & 13.0 & 37.3 & 59.8 \\
Peak 7 & 479 & 13.9 & 33.7 & 54.4 \\
Peak 8 & 368 & 20.7 & 39.0 & 49.4 \\
\hline
\end{tabular}

The data of Figure 3, shows that removals using 110 and $200 \mathrm{mg} / \mathrm{L}$ were similar while these differed to the water treated at $60 \mathrm{mg} / \mathrm{L}$. Lower percentage removals of the peaks occurred as their average molecular weights were lower; for example greater removal occurred in peaks 4 and 5, than for peaks 5 and 6 . Figure 3 shows that NOM with molecular weight higher than $1000 \mathrm{Da}$ is readily removed, though a function of coagulant dose while lower molecular weight compounds are more recalcitrant to removal by alum treatment.

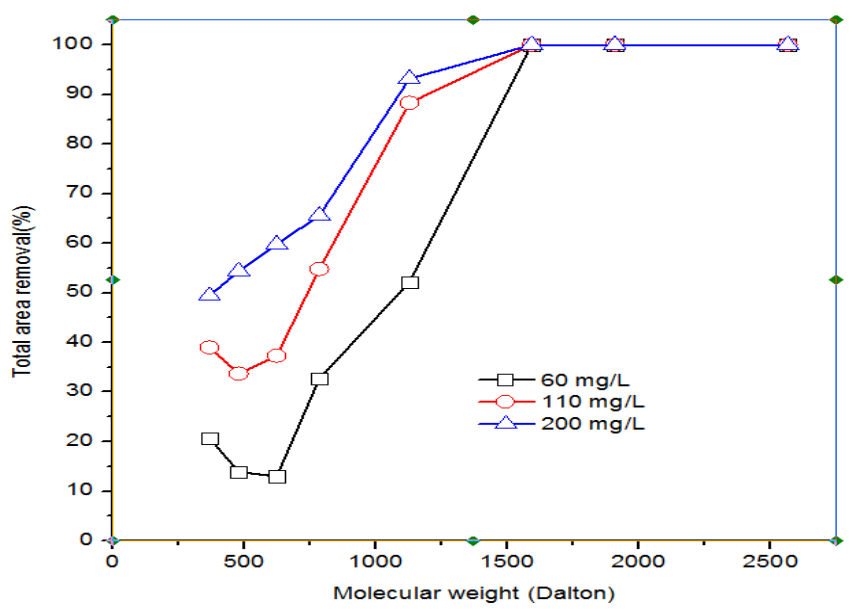

Figure 3: Trends of peak area removal for different coagulant dose.

\subsection{Modelling of Removals of Organics by Alum Treatment}

In order to further develop understanding of the processes by which coagulation leads to removals of the various organic components, the data acquired was fitted to models on the basis that this could allow better comparison of removals, and also with other waters. Figure 4(a) shows the relationship between coagulant 
dose and the removal of total peak area as a function of $\mathrm{pH}$. Using the four data sets of $\mathrm{pH} 5.5,6.0,7.0$ and 8.5, a log-dose response model (Equation 1) was fitted. The removals of total peak areas reach maximum levels at about $100 \mathrm{mg} / \mathrm{L}$ alum where the removal of area achieved is about $80 \%$. At the highest dose tested, $200 \mathrm{mg} / \mathrm{L}$ at $\mathrm{pH} 5.5$, the removal was $92 \%$, while at $\mathrm{pH} \mathrm{8.5}$; this was less, at $73 \%$ removal. From data of the total areas of peaks removed and coagulant doses applied, the following model equation was established that relates peak area to alum dose,

$$
\text { Total Feak Area }=\left(f^{a}\left(1+\left(\frac{D_{0 a}}{b}\right) a_{c}\right)\right)
$$

Where, a is the total area removal at an extreme alum dose (e.g. $200 \mathrm{mg} / \mathrm{L}), \mathrm{b}$ is a variable, the value of which is based on the coagulant $\mathrm{pH}$, as shown in Equation 2, $\mathrm{c}$ is a constant, i.e. -2.15.

$$
b=\frac{1}{0088}+\left(-0.00083 * \mathrm{pH}^{2}\right)+\left(2.55 \times 10^{-2}\right) \mathrm{pH}^{2}
$$

Using equations 1 and 2, the coagulant (alum) dose and $\mathrm{pH}$ required to achieve a specific removal of NOM (target area $\mathrm{pH}$ ) can be obtained, and this may be used for providing information on the control of NOM through the water treatment process. Comparison of actual total peak area removals with the model (Equation 1) data are shown in Table 2. All model fitted data has average error $\sim 3.8 \%$ and standardize error for this model was calculates at various $\mathrm{pH}$ and doses are shown in Table 2.

Typically, NOM in natural waters can be divided into low molecular weight $(<1000 \mathrm{Da})$ hydrophilic compounds that are difficult to remove and high molecular weight $(>1,000 \mathrm{Da}$, such as humic and fulvic acids, hydrophobic) compounds that can be effectively removed by coagulation (Chow et al., 2008). Hence knowledge of the molecular weights of organics is valuable in interpreting the potential of these to be removed by coagulation.

(a)

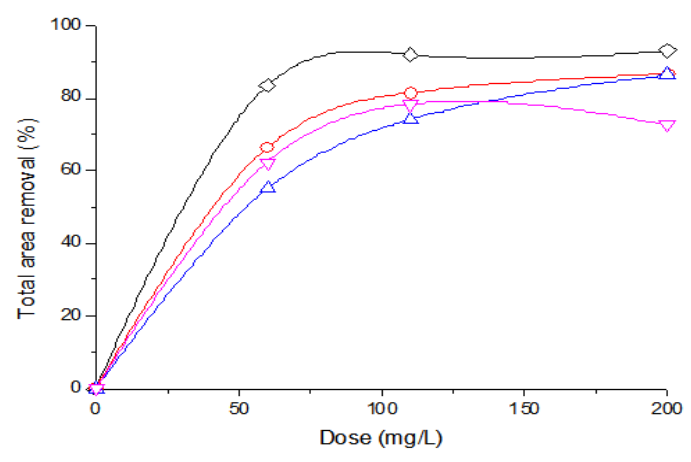

(b)

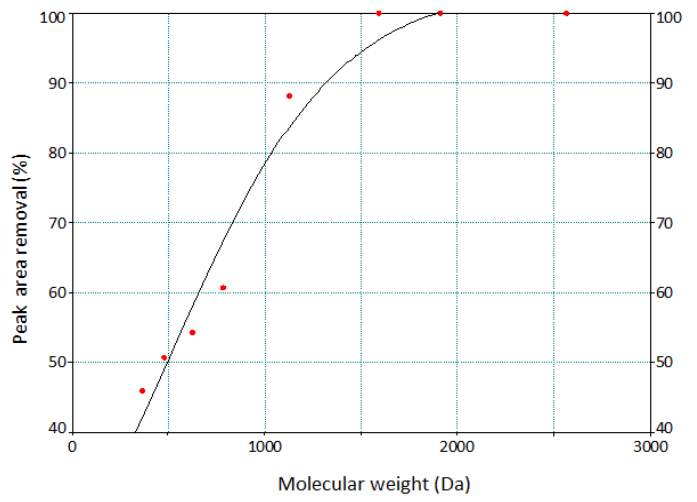

Figure 4: (a) Relationship between alum dose and total area removal for coagulation at pH 5.5 ( $(\hat{)}), \mathrm{pH} 6.0$ $(\mathrm{o}), \mathrm{pH} 7.0(\bar{\nabla})$ and $\mathrm{pH} 8.5(\Delta)$; (b) Example of relationship of molecular weight and total area removal for Morgan water at $110 \mathrm{mg} / \mathrm{L}$ at $\mathrm{pH} 6$

Table 2: Comparison of actual and modelled total area removals, as percentages, at various alum doses, at

\begin{tabular}{|c|c|c|c|c|c|c|c|c|}
\hline \multirow[b]{2}{*}{ Dose } & \multicolumn{2}{|c|}{ pH 5.5} & \multicolumn{2}{|c|}{$\mathrm{pH} 6.0$} & \multicolumn{2}{|c|}{$\mathrm{pH} 7.0$} & \multirow{2}{*}{\multicolumn{2}{|c|}{$\begin{array}{c}\mathrm{pH} 8.5 \\
\text { Model } \\
\text { Fitted } \\
\end{array}$}} \\
\hline & Actual & $\begin{array}{l}\text { Model } \\
\text { Fitted }\end{array}$ & Actual & $\begin{array}{l}\text { Model } \\
\text { Fitted }\end{array}$ & Actual & $\begin{array}{l}\text { Model } \\
\text { Fitted }\end{array}$ & & \\
\hline 60 & 83.5 & 71.6 & 66.4 & 65.3 & 55.1 & 54.5 & 62.4 & 63.0 \\
\hline 110 & 92.0 & 85.5 & 81.5 & 81.2 & 74.1 & 73.3 & 78.3 & 70.6 \\
\hline 200 & 93.0 & 90.2 & 86.8 & 86.9 & 86.3 & 80.8 & 72.6 & 72.9 \\
\hline $\begin{array}{c}\text { Standardize } \\
\text { error }\end{array}$ & i & 5.69 & & 0.83 & & 3.05 & & 5.30 \\
\hline
\end{tabular}
$\mathrm{pH} 6.0$ 
A model of the relationship between the molecular weight of organics and their removal from the River Murray water was developed using the peak-fitted data of HPSEC derived from jar tests conducted at $\mathrm{pH} 6$ and of the various doses used (Figure $4 \mathrm{~b}$ ). By using 8 different points of peak areas removed, the following relationship was determined by fitted the data into Table curve software based on the best $\mathrm{R}^{2}$ value and best fit for all $\mathrm{pH}$.

$$
\text { Area removal }(\%)=a k(1+\exp (-(\text { Molecular welght stze }-b) \xi c))
$$

Where, $\mathrm{a}=100 \%$; removal of peak area , $\mathrm{b}=$ value of molecular weight at $50 \%$ removal of total area, $\mathrm{c}=$ constant value; 285.1 for the River Murray water at time of collection

The value of ' $b$ ' for this water can be related to the coagulant dose; as follows:

$$
b=1 \xi\left(0.00271+0.00271 /\left(-4,418 \xi\left(\text { Doss }^{*} 2\right)\right)\right)
$$

From Equation 3, the removals of HPSEC areas for different peaks with specific molecular weights can be estimated. Higher molecular weight natural organic matter (above $\sim 1100 \mathrm{Da}$ ) can be removed even at lower doses while organics of low molecular weight require use of higher coagulant doses (referred to as enhanced coagulation) to maximize removals of low molecular weight NOM (Table 1). The models developed provide further information in the understanding of the removal of organics by coagulation and allow for comparison of these removals, based on the character of organics in drinking water supplies.

Based on regression analysis for DOC removal and total area removal, it shows that there is a good relationship between DOC removal and total area removal. The coefficient for this regression is 3.68 while the $\mathrm{R}^{2}$ and adjusted $\mathrm{R}^{2}$ are 0.92 and 0.91 respectively. The DOC removal can be calculated by following equation:

$$
y=0.823 x+3.68
$$

Where,

$\mathrm{x}=$ Predicted area removal $(\%)$

$\mathrm{y}=\mathrm{DOC}$ removal $(\%)$

\section{CONCLUSION}

In this study, the application of peak fitting of HPSEC data was demonstrated, providing information on the molecular weight distribution of NOM in drinking water, and the presence of different groups of compounds with different molecular weights. Experimental data was used to assess relationships between the removal capacity of organic matter by coagulation and their molecular weight profiles. Models were developed for the relationships between the HPSEC peak area by peak fitting tool, coagulant doses and $\mathrm{pH}$, after peak fitted areas were standardized to percentages. These models may be applied to assess the treatability of NOM by coagulation, based on HPSEC peak fitted data and also allow for enhanced comparison of the treatability of organics in waters as their characters change over time. The further development of the models of HPSEC data to ones that can be generically applied is a subject for future investigation.

\section{REFERENCES}

Baxter, C.W., Shariff, R., Stanley, S.L., Smith, D.W., Zhang, Q. and Saumer, E.D. (2002). Model based advanced process control of coagulation. Water Science and Technology, 45(4-5), 9-17.

Bazer-Bachi, A., Puech-Coste, E., Aim, B.R. and Probst, J.L.(1990). Mathematical modelling of optimum coagulant dose in water treatment plant, Revue Des Sciences De L'eau. 3, 377-397.

Chow, C.W.K., Fabris, R., van Leeuwen, J., Wang, D.S. and Drikas, M.(2008). Assessing natural organic matter treatability using high performance size exclusion chromatography. Environmental Science and Technology, 42 (17), 6683-6689.

Daly, R., van Leeuwen, J. and Holmes, M. (2007). Modelling Coagulation to Maximise Removal of Organic Matter A Pilot Plant and Laboratory Based Study: Chemical Dose Prediction. CRC for Water Quality and Treatment, Salisbury, Research Report No. 36 Australia ISBN 18766 1661X 
Aslam et al., Peak fitting and modelling of NOM removal by coagulation from River Murray...

Edwards, M. (1997). Predicting DOC removal during enhanced coagulation. Journal of the American Water works Association 89(5) 78-89.

Goslan. H. Emma, Voros, S., Banks, J., Wilson. D., Hillis, P., Campbell, T.A., Persons, A. S. (2004). A model for predicting dissolved organic carbon distribution in a reservoir water using fluorescence spectroscopy.Water Reasearch,38(3) 783-791.

Kastl, G., Fisher, I., Sathasivan, A. and van Leeuwen, J. (2004). Modelling DOC removal by enhanced coagulation. Journal of the American Water works Association, 96(2), 79-89.

van Leeuwen, J., Holmes, M., Heidenreich, C., Daly, R., Fisher, I., Kastl, G., Sathasivan, A., and Bursill, D. (2003). Modelling the Application of Inorganic Coagulants and pH Control Reagents for Removal of Organic Matter from Drinking Waters. MODSIM Integrative Modelling of Biophysical, Social and Economic Systems for Resource Management Solutions, Townsvillle, 1835-1840.

van Leeuwen, J., R. Daly, M. Holmes. (2005). Modelling the Treatment of Drinking Water to Maximize, dissolved organic matter removal and minimize disinfection by-product formation. Desalination, 177, 81-89.

van Leeuwen, J., C.W.K. Chow, Fabris, R., Drikas, M., and Spark, K. (1999b). Enhanced coagulation for dissolved organic carbon removal in conventional treatment with alum.AWWA $18^{\text {th }}$ Federal Convention proceeding, Adelaide, $11-14^{\text {th }}$ April, CDROM. 